\title{
RUNNING ANAEROBIC SPPINT TEST, LACTATE MINIMUM AND CRITICAL VELOCITY PROTOCOL IN SHUTTLE FUTSAL TESTING
}

\author{
Leonardo Henrique Dalcheco Messias, 1, A, B, C, D Vinícius Carvalho de Andrade, 2, A, B, C, D \\ KauêTomazine Rosante, ${ }^{2, A, B, C}$ Tiago Buzatto de Lima, 2, A, B, C \\ Ricardo Alexandre Rodrigues Santa Cruz,, ${ }^{3, B}$ Ramon Martins de Oliveira, ${ }^{2, B}$ \\ Fúlvia de Barros Manchado-Gobatto 1 , A, B, C, D
}

\footnotetext{
${ }^{1}$ Laboratory of Applied Sport Physiology, School of Applied Sciences, University of Campinas - UNICAMP, Brazil

${ }^{2}$ Methodist University of Piracicaba - UNIMEP, Brazil

${ }^{3}$ University of Roraima

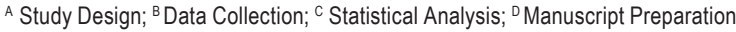

\author{
Address for corpespondence: \\ Fúlvia de Barros Manchado-Gobatto, PhD \\ Laboratory of Applied Sport Physiology \\ School of Applied Sciences, University of Campinas - UNICAMP \\ Pedro Zaccaria St. 1300, Santa Luíza, 13484-350 Limeira, SP, Brazil \\ E-mail: fbmanchado@yahoo.com.br
}

\begin{abstract}
Ahstract. The aims of this study were to investigate whether the running anaerobic sprint test, lactate minimum and critical velocity protocol can be applied in shuttle futsal testing, and to investigate if these protocols provide related variables. Seven male welltrained futsal players were evaluated. The lactate minimum test $\left(\mathrm{Lac}_{\mathrm{Min}}\right)$ consisted of three phases: a) a hyperlactatemia phase using the running anaerobic sprint test (RAST); b) recovery phase; c) an incremental shuttle test for the lactate minimum speed (LMS) determination. Successful rate (SR) was calculated for feasibility analysis. Peak, mean and minimum power and fatigue index were obtained by the RAST application (six bouts - 35 meters). The critical velocity protocol (CV) was applied through three exhaustive shuttle tests (12, 13 and $14 \mathrm{~km} / \mathrm{h}$ ) with distances of 20 meters. Critical velocity (Cv) and anaerobic running capacity (ARC) were analysed by the linear (velocity vs.1/tlim) and hyperbolic (time vs.velocity) models. Fits of regression $\left(R^{2}\right)$ were considered as the main result for feasibility analysis of CV. ANOVA showed a difference between linear (11.04 $\pm 0.55 \mathrm{~km} / \mathrm{h})$ and LMS $(9.67 \pm 0.50 \mathrm{~km} / \mathrm{h})$, and no significant correlation was observed between them. High SR (85.71\%) was observed for $\mathrm{LaC}_{\mathrm{Min}}$, and high $\mathrm{R}^{2}$ for $\mathrm{CV}$ (linear- $\mathrm{R}^{2}=0.99$ \pm 0.04 ; hyperbolic- $R^{2}=0.98 \pm 0.02$ ). Overall, the RAST, $L_{a} a_{M i n}$ and $C V$ can be successfully applied in shuttle futsal testing, nonetheless, precaution is necessary since the test results were not related.
\end{abstract}

Key WOrll: : Aerobic-anaerobic transition, fitness testing, exercise evaluation

\section{Introduction}

Similar to soccer, but played in restricted spaces, futsal is an intermittent sport requiring both aerobic and anaerobic metabolisms during matches (Rebelo et al. 2011). Despite the fact that the scientific community have 
been studying this sport in several aspects (Barbero-Alvarez et al. 2008; Castagna and Barbero-Alvarez, 2010; Castagna et al. 2009; Dogramaci et al. 2011), there is a lack of reports around the application of evaluation protocols for aerobic and anaerobic parameters determination.

Proposed by Zacharogiannis et al. (2004), the running anaerobic sprint test (RAST) is an Wingate Anaerobic Test adaptation (Bar-Or et al. 1977) for running. This test consists of six 35-m maximal bouts with 10 seconds recovery between efforts. Certain advantages are recognized by means of RAST application, such as the obtainment of parameters related to anaerobic power, low financial cost, necessity of only one evaluation day and easy application in the field. Additionally, RAST reliability and validation has already been investigated (Balciunas et al. 2006; Zagatto et al. 2009). Although this protocol has also been applied for military personnel (Zagatto et al. 2009), handball athletes (Roseguini et al. 2008) and well trained subjects (Deminice et al. 2013), its application in shuttle futsal testing is unknown. On account of the great anaerobic metabolism participation during futsal matches (Rebelo et al. 2011), the data from RAST may be valid for both controlling and prescribing training.

The so-called lactate minimum test $\left(\mathrm{LaC}_{\mathrm{Min}}\right)$ (Tegtbur et al. 1993) was classically proposed in running and subsequently adapted to cycling (Maclntosh et al. 2002) and swimming (Ribeiro et al. 2003) exercises. This test is started by a short supramaximal exercise inducing hyperlactatemia followed by short rest period to allow the equilibrium between muscle and blood lactate concentration ([Lac]) (Faude et al. 2009). Subsequently the rest period, an incremental phase is initiated. In the first stages of low intensities, the [Lac] is expected to fall, and in the next stages of higher intensities to rise again. The lowest point of the "U-shaped" lactate curve is assumed as the lactate minimum speed (LMS), which is related to the intensity where the [Lac] is in equilibrium (Faude et al. 2009), or in other words the lactate threshold (Kindermann et al. 1979). Despite the interesting possibility of the LMS assessment in only one evaluation session, few scientific information is available regarding the Lac $_{\text {Min }}$ in shuttle testing (Ribeiro et al. 2003). Additionally, there is no data about the application of this test in shuttle futsal testing.

Based on mathematical analysis, the critical velocity protocol (Lloyd 1966; Wakayoshi et al. 1992) is an analogous of the critical power concept proposed by Monod and Scherrer (1965). The critical velocity $\left(\mathrm{C}_{\mathrm{v}}\right)$ and the anaerobic running capacity (ARC) are known as the aerobic and anaerobic estimates provided by this test. While the $C_{V}$ is related to the maximum rate of work performed for a long time without fatigue, the ARC is recognized as the finite amount of work that can be used above $C_{V}$ (Jones et al. 2010). In view of the mathematical approach beyond this test, several studies have applied linear and nonlinear (i.e. hyperbolic) mathematical models to assess the aerobic/anaerobic estimates (Bull et al. 2000; Copp et al. 2010; Gobatto et al. 2013; D. J. Housh et al. 1990; T. J. Housh et al. 2001). Also, this approach is an interesting way to ease the estimates obtainment, since the necessary mathematical knowledge required by this protocol may hamper the analysis of its results. Taking into account the necessity to improve both aerobic and anaerobic capacity of futsal players for better performance, and the relationship of critical velocity estimates with these capacities, the protocol adaptation in shuttle futsal testing is an interesting proposal.

Considering that the application of RAST, $\mathrm{LaC}_{\mathrm{Min}}$ and critical velocity protocol in futsal may provide relevant information to improve athlete's performance, the aims of this study were to investigate whether these tests can be applied in shuttle futsal testing and to investigate if these protocols provide related variables. 


\section{Methods}

\section{Participants}

Seven well-trained futsal male athletes (ages $22 \pm 2$ years old, body mass79.4 $\pm 13.9 \mathrm{~kg}$ and height $176 \pm 8 \mathrm{~cm}$ ) were evaluated. Prior to the evaluate sessions, the athletes were asked to keep the same individual food/hydration habits and avoid hard physical activity, alcohol and caffeine ingestion. After a detailed explanation about the risks and objectives of the study, a written informed consent was signed by all participants. All experiments were approved by the Ethics Committee of the Methodist University of Piracicaba (no. 33/10) and performed in accordance with the ethical standards of the 1964 Declaration of Helsinki.

\section{Design}

For RAST, $\mathrm{Lac}_{\mathrm{Min}}$ and CV applications and assessment of its variables, each athlete participated in four evaluation sessions separated by 24 hours between sessions. Every evaluation session was applied in an official futsal court and took place at the same time of the day $( \pm 1 \mathrm{~h})$. Moreover, athletes wore the same running shoe and lightweight running kit for all tests. In the first session the athletes performed the RAST and $\mathrm{Lac}_{\text {Min }}$ test for anaerobic and aerobic variables assessment, respectively. The RAST was applied in the first phase of the Lac $_{\text {Min }}$ test. In the following three evaluation sessions, the CV protocol was applied randomized. The aerobic and anaerobic variables provided by this protocol were analysed using both linear and hyperbolic mathematical models. Before each of the tests, the athletes performed 10 min of self-paced jogging as a warm-up.

\section{Running Anaerobic Sprint Test}

After weighed, the athletes performed six maximal bouts of 35 meters in a futsal court, with passive recovery of 10 seconds between bouts. Time (s) of each bout was recorded with a timer (Casio, HS - 30 W - N1). Peak power $\left(\right.$ Peak $\left._{\text {power }}\right)$, mean power $\left(\right.$ Mean $\left._{\text {power }}\right)$ and minimum power $\left(\operatorname{Min}_{\text {power }}\right)$ were calculated by: Power $=($ Body mass $\times$ Distance $\left.^{2}\right) /$ Time $^{3}$ (Zagatto et al. 2009). Maximum velocity $\left(V_{\operatorname{maxR}}\right)$ was calculated by: $V_{\operatorname{maxR}}=$ Distance $/$ fastest bout. Fatigue Index (FI) was calculated according to Fitzsimons et al. (1993): FI = (100 × (total sprint time I ideal sprint time)) - 100; where Total sprint time $(\mathrm{TT})=$ sum of all the sprint times and Ideal sprint time $=$ number of sprints $\times$ fastest sprint time.

\section{Lactate Minimum Test}

The lactate minimum test consisted of three phases (Figure 1a): 1st phase - Hyperlactatemia induction Hyperlactatemia induction was conducted by the RAST; 2nd phase - Passive recovery - After the hyperlactatemia induction, athletes performed a passive recovery for 8 minutes. 3nd phase - Incremental test - Right after the passive recovery, an incremental test was performed in stages of 3 minutes in shuttle exercise with distances of 20 meters. Velocity was controlled by a metronome considering as predictive loads the velocities of 7, 9, 10 and $12 \mathrm{~km} / \mathrm{h}$. Lactate minimum speed (LMS) was determined as the lowest lactate value of "U-shaped" curve between blood lactate concentration and load (Figure 1b). Capillary blood samples were collected before and at the third, fifth and seventh minute after RAST, and at the end of each stage of incremental phase. Each blood collection took approximately 20 seconds. Successful rate (SR) of the $\mathrm{Lac}_{\text {min }}$ was determined considering $R^{2} \geq 0.80$ in a polynomial second order fit, according to Araujo et al. (2007). 

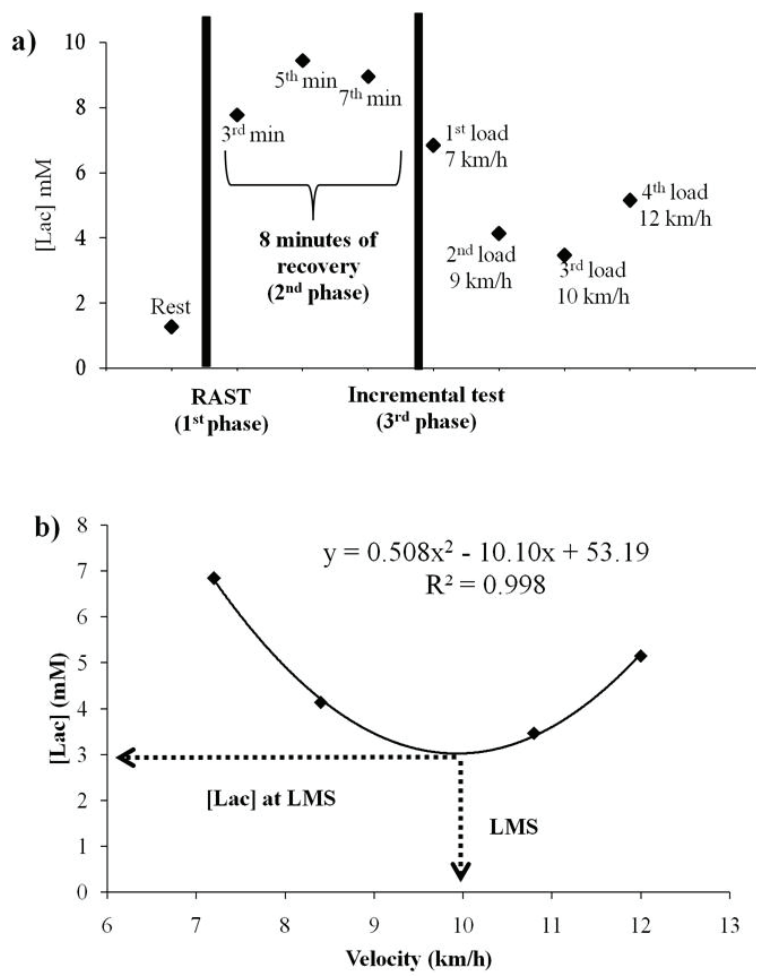

Figun 1. a) Three phases of the lactate minimum test and the respective [Lac] at each phase. b) Example of "U-shaped" curve of blood lactate concentration vs. velocity in the incremental phase

\section{Critical Velocity Protocol}

Athletes performed three exhaustive shuttle tests, with 20 meters of distance in 12, 13 and $14 \mathrm{~km} / \mathrm{h}$ velocities controlled by a metronome. Individual time to exhaustion (tlim) was recorded in each test. Exhaustion criteria were considered as the non-maintenance of previously established velocity in two consecutive 20 meters or voluntary exhaustion. Critical velocity $\left(\mathrm{C}_{\mathrm{V}}\right)$ and anaerobic running capacity $(\mathrm{ARC})$ (aerobic and anaerobic variables, respectively), were obtained by two mathematical models. 1) linear model of velocity (v) vs. 1/tlim proposed by Hughson et al. (1984), with $C_{V}\left(C_{V L i n e a r}\right)$ related to intercept-y and $A R C\left(A R C_{\text {Linear }}\right)$ to slope of regression (Figure 2a); and 2) hyperbolic model of time ( $t$ ) vs. velocity (v) (Monod andScherrer 1965), with $C_{V}\left(C_{V H y p e r b o l i c}\right)$ related to asymptote of $x$ axis and $A R C$ ( $A R C_{\text {Hyperbolic }}$ ) to slope of regression (Figure $2 b$ ). $R^{2}$ data from both mathematical models were considered as the main result for the feasibility application analysis of the CV protocol. 
a)

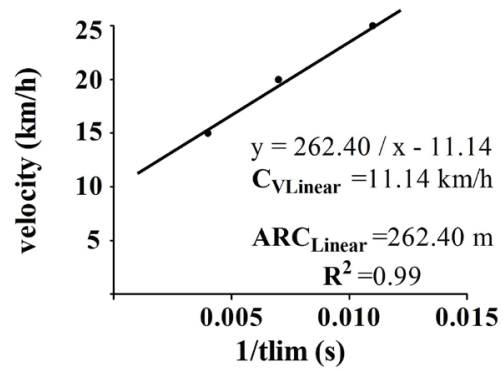

b)

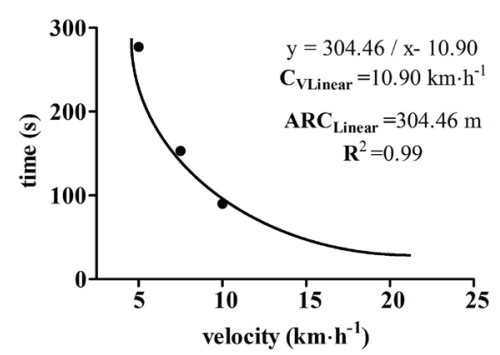

Figure 2. a) Example of the velocity vs. 1/time (1/tlim) model, with the $C_{V L \text { Linear }}$ related to intercept-y and the $A R C_{\text {Linear }}$ to the slope of regression. b) Example of the time vs. Velocity model, with the $\mathrm{CV}_{\text {Hyperbolic }}$ related to asymptote of $\mathrm{x}$ axis and $\mathrm{ARC}_{\text {Hyperbolic }}$ to the slope of regression.

\section{Blood Sample}

Capillary blood samples were collected from athlete's ear lobes in $25-\mu \mathrm{L}$ heparinised capillaries. Blood samples were transferred to $1.5-\mathrm{mL}$ micro tubes (Eppendorf) containing $200 \mu \mathrm{L}$ of TCA (tricloroacetic acid). In order to analyse blood lactate concentration enzymatically, samples were stored at a $-30^{\circ} \mathrm{C}$ temperature, shaken in a magnetic stirrer and centrifuged (3000 rpm). The homogenate was again mixed and immediately incubated for 20 minutes at $37^{\circ} \mathrm{C}$. Samples were read in a spectrophotometer with a $340 \mathrm{~nm}$ wavelength. Blood lactate concentrations were then assayed using an enzymatic method (Engel and Jones 1978) and expressed in $\mathrm{mM}$.

\section{Statistical Analysis}

Statistical analysis was carried out using a statistical software package (Statistic 7.0, Statsoft, Tulsa, USA). Mean and standard deviation were calculated for all studied variables. Before using a parametric analysis, the normal distribution and homogeneity of data were verified by Shapiro-Wilk and Levene tests, respectively. Results from $\mathrm{Lac}_{\min }$ test and CV protocol were compared using ANOVA one-way for a paired sample. ANOVA one-way was also applied for comparison between bout times of RAST. Student t-test was applied for comparison of $\mathrm{C}_{V}$ and ARC between the mathematical models. Pearson product moment correlation was applied for relationship analysis. Confidence intervals were also calculated in relationship analysis (Pearson product moment) and standard deviation with $a=0.05(\sigma / \sqrt{ } n)$. In all cases, statistical significance was set at $P<0.05$.

\section{Results}

Descriptive results from RAST are shown in Table 1. No differences were visualized between bouts times (Bout 1 - $5.27 \pm 0.31 \mathrm{~s}$; Bout $2-5.11 \pm 0.48 \mathrm{~s}$; Bout $3-5.49 \pm 0.42 \mathrm{~s}$; Bout $4-5.63 \pm 0.19 \mathrm{~s}$; Bout $5-5.64 \pm 0.26 \mathrm{~s}$; Bout $6-5.79 \pm 0.38 \mathrm{~s}$ ). For $58 \%$ of athletes, the $V_{\operatorname{maxR}}$ was attained at Bout $1,14 \%$ at Bout $2,14 \%$ at Bout 3 and $14 \%$ at Bout 6 . 
Tahle 1. Peak Power $\left(\right.$ Peak $\left._{\text {power }}\right)$, mean power $\left(\right.$ Mean $\left._{\text {power }}\right)$, minimum power $\left(\operatorname{Min}_{\text {power }}\right)$, maximum velocity $\left(\mathrm{V}_{\operatorname{maxR}}\right)$, fatigue index $(\mathrm{FI})$ and total sprint time (TT) obtained from RAST

\begin{tabular}{lccccccccc} 
& $\begin{array}{c}\text { Peak } \\
\text { power }\end{array}$ & $\begin{array}{c}\text { Mean }_{\text {power }} \\
(\mathrm{W})\end{array}$ & $\begin{array}{c}\mathrm{Min}_{\text {power }} \\
(\mathrm{W})\end{array}$ & $\begin{array}{c}\text { Peak }_{\text {power }} \\
(\mathrm{W} / \mathrm{kg})\end{array}$ & $\begin{array}{c}\text { Mean }_{\text {power }} \\
(\mathrm{W} / \mathrm{kg})\end{array}$ & $\begin{array}{c}\text { Min }_{\text {power }} \\
(\mathrm{W} / \mathrm{kg})\end{array}$ & $\begin{array}{c}\mathrm{V}_{\operatorname{maxR}} \\
(\mathrm{km} / \mathrm{h})\end{array}$ & $\begin{array}{c}\mathrm{FI} \\
(\%)\end{array}$ & $\begin{array}{c}\mathrm{TT} \\
(\mathrm{s})\end{array}$ \\
\hline Mean & 662.98 & 528.93 & 413.52 & 10.48 & 7.91 & 6.00 & 24.67 & 8.50 & 33.27 \\
$\mathrm{SD}$ & 117.42 & 79.00 & 76.33 & 2.79 & 0.85 & 0.87 & 1.42 & 5.08 & 0.89 \\
\hline $\mathrm{Cl}$ & $75.66-258.57$ & $50.91-173.96$ & $49.19-168.08$ & $1.80-6.14$ & $0.55-1.87$ & $0.56-1.92$ & $0.94-2.89$ & $3.36-10.34$ & $0.56-1.92$ \\
$(\mathrm{a}=0.05)^{\#}$ & & & & & &
\end{tabular}

$\mathrm{SD}=$ standard deviation; $\mathrm{Cl}=$ Upper and lower confidence limits of confidence interval for SD.

$\mathrm{LaC}_{\text {Min }}$ test results are shown in Table 2. After first phase, high [Lac] were visualized at the third (8.71 $\pm 1.70 \mathrm{mM})$, fifth $(9.07 \pm 1.33 \mathrm{mM})$ and seventh $(9.63 \pm 1.61 \mathrm{mM})$ minute in the second phase. Only in one case the $\mathrm{R}^{2}$ was lower than $0.80\left(R^{2}=0.67\right)$, resulting in the high success rate of $85.71 \%$.

Table 2. Lactate minimum speed (LMS), blood lactate concentration at lactate minimum speed ([Lac] at LMS), $\mathrm{R}^{2}$ of second polynomial and successful rate (SR) obtained from the $\mathrm{Lac}_{\text {Min }}$ test

\begin{tabular}{|c|c|c|c|c|}
\hline & $\begin{array}{c}\text { LMS } \\
\left(\mathrm{km} \times \mathrm{h}^{-1}\right)\end{array}$ & $\begin{array}{c}\text { [Lac] at LMS } \\
(\mathrm{mM})\end{array}$ & $\mathrm{R}^{2}$ & $\begin{array}{l}\text { SR } \\
(\%)\end{array}$ \\
\hline Mean & 9.67 & 4.36 & 0.90 & $85.71^{*}$ \\
\hline SD & 0.50 & 1.57 & 0.10 & -- \\
\hline $\begin{array}{l}\mathrm{Cl} \\
(\alpha=0.05)^{\#}\end{array}$ & $0.32-1.10$ & $1.01-3.46$ & $0.06-0.22$ & -- \\
\hline
\end{tabular}

* Data in absolute percent.

$\mathrm{SD}=$ standard deviation; $\mathrm{Cl}=$ Upper and lower confidence limits of confidence interval for SD

CV protocol results from the two mathematical models are shown in Figure 3. No differences were visualized for $C_{V}\left(C_{V L \text { inear }}=11.10 \pm 0.55 \mathrm{~km} / \mathrm{h} ; C_{V H y p e r b o l i c}=10.70 \pm 0.65 \mathrm{~km} / \mathrm{h} ; \mathrm{P}=0.690\right)$ (Figure 3a) and ARC (ARC Linear $_{\text {. }}$ $=281.22 \pm 64.61 \mathrm{~m} ; A \mathrm{RC}_{\text {Hyperbolic }}=354.25 \pm 113.14 \mathrm{~m} ; \mathrm{P}=0.198$ ) (Figure $\left.3 \mathrm{~b}\right)$. A significant relationship was only visualized for $C_{V}(r=0.77 ; P=0.04 ; C l=0.04-0.96)$. High $R^{2}$ were observed both for linear $\left(R^{2}=0.96 \pm 0.04\right)$ and hyperbolic $\left(R^{2}=0.98 \pm 0.02\right.$ ) models (Figure $3 c$ ). Regarding the times of exhaustion in each effort, a rage between 100.7 and 333.1 seconds was visualized (Figure $3 d$ ).

ANOVA pointed differences only for LMS and $C_{V L \text { Linear }}(P=0.004)$. In addition, the correlations between $L M S$ and $C_{V}$ were not significant (Figure $\left.4 a, 4 b\right)$. Nevertheless, no relationship was visualized between ARC and all other RAST results. 
a)

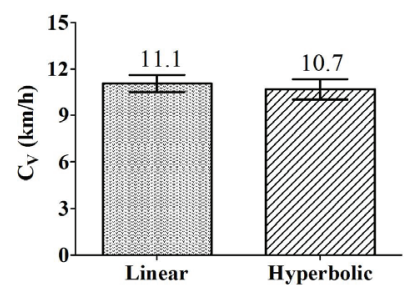

c)

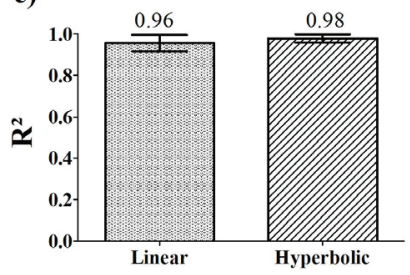

b)

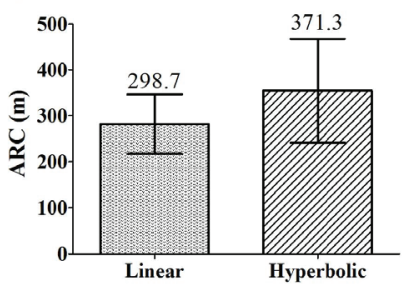

d)

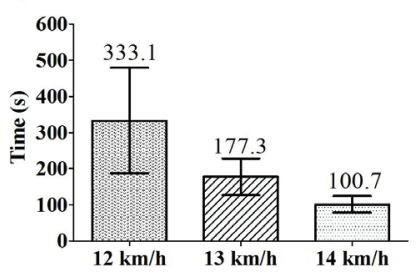

Figulp 3. a) Results of aerobic estimate $\left(C_{V}\right)$ obtained in the critical velocity protocol by two mathematical equivalent equations. b) Results of anaerobic estimate (ARC) obtained from the critical velocity protocol by two equivalent equations. c) Fits of regression ( $\left.R^{2}\right)$ obtained by the two mathematical equivalent equations. d) Time of exhaustion from each effort in the critical velocity protocol

a)

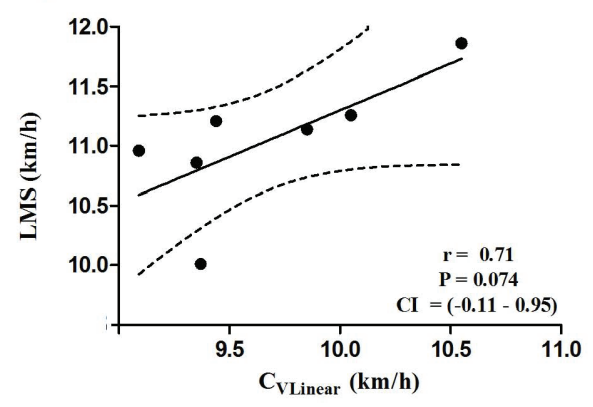

b)

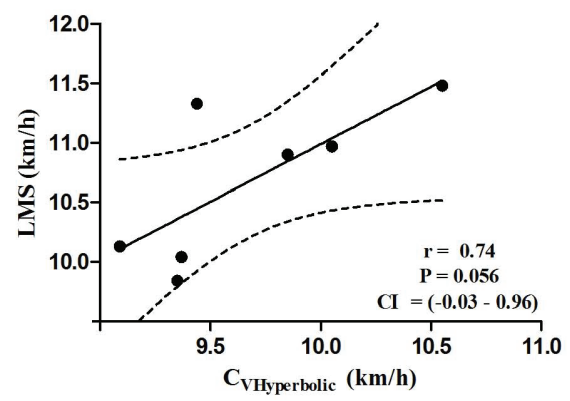

Figulle 4. Correlations between $\mathrm{LaC}_{\text {Min }}$ test and CV protocol results. a) Correlation between LMS and $\mathrm{C}_{\mathrm{VLinear}}$. b) Correlation between LMS and $\mathrm{C}_{V \text { Hyperbolic }}$; LMS - lactate minimum speed; $\mathrm{C}_{\mathrm{VLinear}}$ - aerobic estimate from the linear model; $\mathrm{C}_{\mathrm{VHyperbolic}}$-aerobic estimate from the linear model

\section{Discussion}

This is the first study to investigate the RAST, $\mathrm{LaC}_{\mathrm{Min}}$ and CV application for futsal players. We have shown that these evaluation protocols can be successfully applied in shuttle futsal testing without impairing the assessment of aerobic and anaerobic variables provided by these protocols. On the other hand, it is not possible to affirm that those variables can be interchangeably used, since the aerobic and anaerobic results were not related. 
Some factors are necessary to ensure the $\mathrm{Lac}_{\text {Min }}$ application. Due to the fact that the incremental test (i.e third phase) is initiated with high [Lac], the kinetic of this metabolic product in the bloodstream is expected to fall in the firsts incremental stages and rise again in the subsequent stages. Thus, a "U-shaped" curve between intensity (i.e velocity) and [Lac] is visualized, which is necessary to identify the minimum point, or the lactate minimum speed (i.e. LMS). Moreover, Tegtbur et al. (1993) proposed that a second order polynomial fit is characteristic in the curve between intensity and [Lac] in this test. In this sense, the coefficient of determination $\left(R^{2}\right)$ from the polynomial fit is an intuitive data to ensure the $\mathrm{LaC}_{\text {Min }}$ success application. In this way, studies have been using the "U-shaped" curve followed by a high coefficient of determination $\left(R^{2}\right)$ as successful rate criteria for $\mathrm{LaC}_{\mathrm{Min}}$ test application. Despite the relevance of this rate, its values are not shown. The only study that established a rate value for $\mathrm{LaC}_{\mathrm{Min}}$ application was conducted by Araujo et al. (2007). They concluded that is necessary to assess $R^{2} \geq 0.80$ for the $\operatorname{Lac}_{\text {Min }}$ test success application.

It is valid to state that depending on the type of exercise, the $\mathrm{R}^{2}$ from the polynomial fit can be modified. In the present study, the $\mathrm{LaC}_{\mathrm{Min}}$ was adapted in a shuttle exercise testing, making necessary constantly acceleration and deceleration by the futsal players in the incremental test. This dynamic could influence the production of lactate by muscle cells or its removal from the bloodstream. Considering the "U-shaped" is based on the [Lac], if the type of exercise influences in the blood lactate, the lactate curve could be right or left shifted. Consequently, the LMS could be also overestimated or underestimated, compromising the $\mathrm{LaC}_{\mathrm{Min}}$ test application. Despite the fact that the above cited factors could impair the LMS determination, our results showed that only one athlete obtained low $\mathrm{R}^{2}$ $\left(R^{2}=0.67\right)$, resulting in $85.71 \%$ of success rate.

This result is favourable for the $\mathrm{LaC}_{\mathrm{Min}}$ regarding its application in shuttle exercise. For futsal this data is even more interesting. Inside training and matches the athletes must constantly accelerate and decelerate in several situations (Rodrigues et al. 2011). Thus, the high success rate obtained by means of $\mathrm{Lac}_{\mathrm{Min}}$ application in shuttle exercise highlights the futsal specificity in this test. Whether the Lac $_{\text {Min }}$ adaptation for futsal was accomplished considering its classic proposal in continuous exercise (Tegtbur et al. 1993), then the futsal specificity would not be considered. Thus, based on our results, it is possible to suggest that at least for futsal, the Lac $_{\text {Min }}$ application in shuttle exercise is more specific than in continuous exercise. Furthermore, training sessions based on the LMS obtained in shuttle exercise would be more effective for performance improvement.

Another interesting data was the successful application of the RAST inside the Lac $_{\text {Min }}$ test. Usually the RAST is solely applied to assess parameters related to the anaerobic power. In the present study, we have applied this test for both assessments of its variables as well as to induce hyperlactatemia in the Lac $_{\text {Min }}$ first phase. High [Lac] were observed in $\mathrm{Lac}_{\text {Min }}$ test second phase, concluding that the RAST was effective for its purpose in this study. Despite these important information, it is valid to highlight that the RAST inclusion in $\mathrm{LaC}_{\mathrm{Min}}$ first phase is even more relevant. Considering that the $\mathrm{Lac}_{\mathrm{Min}}$ application requires only one evaluation day, and that the RAST can be successfully applied in this test, the $\mathrm{Lac}_{\mathrm{Min}}$ test becomes a complete evaluation protocol for futsal players. In other words, our results suggest that by means of $\mathrm{Lac}_{\text {Min }}$ application using the RAST, futsal coaches may assess both anaerobic

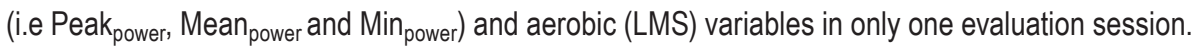

Widely studied, the CV protocol has been applied in different exercises (Berthoin et al. 2006; Fukuda et al. 2011; Toubekis et al. 2011). In addition, the CV protocol analysis by different mathematical models has been performed using different ergometer for humans (Bull et al. 2000; D.J. Housh et al. 1990; T.J. Housh et al. 2001) as well as for rodents (Copp et al. 2010; Gobatto et al. 2013). However, it is well established that albeit mathematically 
equivalent, the transformation from linear to a nonlinear model does not always promote similar estimates (Jones et al. 2010). Instead, in the present study no difference was visualized between estimates from linear and hyperbolic models (Figure 3a, 3b). Similar to $\mathrm{LaC}_{\text {Min }}$ test, in CV protocol studies use the $\mathrm{R}^{2}$ in the respective mathematical model as a data related to its successful application. In this way, high $R^{2}$ values were visualized in both models (Figure $3 c$ ). These results suggest that independently of mathematical model, the aerobic and anaerobic parameters may be obtained in shuttle futsal testing.

Considering the comparison between the aerobic parameters from $\mathrm{LaC}_{\mathrm{Min}}$ test and $\mathrm{CV}$ protocol, we have shown that only LMS and $\mathrm{CV}_{\text {Linear }}$ were different. Despite the fact that this absence of statistical difference between LMS and $\mathrm{C}_{\mathrm{VHyperbolic}}$ suggests that these two indicators match in similar physiological significance, it is worth noting that absolute results were differentiated by approximately $1 \mathrm{~km} / \mathrm{h}\left(\mathrm{LMS}=9.67 \pm 0.50 \mathrm{~km} / \mathrm{h} ; \mathrm{C}_{\mathrm{VHyperbolic}}=10.70\right.$ $\pm 0.65 \mathrm{~km} / \mathrm{h}$ ). For training prescription these results can make great difference. These contradictory differences about LMS, $\mathrm{C}_{V L \text { inear }}$ and $\mathrm{C}_{V H y p e r b o l i c}$ are not surprising, since current knowledge establishes $L M S$ and $\mathrm{C}_{V}$ in different physiological significance. $C_{V}$ is actually described as the intensity of transition between intense and severe domain (Jones et al. 2010). On the other hand, Tegtbur et al. (1993) define LMS as an maximal lactate steady state intensity predictor. Even some studies contradict this (Carter et al. 1999; Jones and Doust 1998), other support the Tegtbur hypothesis (Knoepfli-Lenzin and Boutellier 2011; Maclntosh et al. 2002).

Regarding the relationship between RAST and CV results, while high Peak Power, $_{\text {, Mean }}$ Power $_{\text {and }} \mathrm{V}_{\text {MaxR }}$ are related to anaerobic power, low TT could be related to a fatigue resistance, or in other words, anaerobic capacity. Theoretically, the ARC should be relative to a finite amount of work performed above $C_{V}$ (Monod and Scherrer 1965). However, while the $C_{V}$ is considered as the intensity transition between the heavy and severe intensity domains (Jones et al. 2010), several studies have criticized the physiological meaning of ARC (Dekerle et al. 2006; Zagatto and Gobatto. 2012; Zagatto et al. 2008). Supporting this idea, in the present study no relationship was observed between ARC and RAST results. This absence of relationship may be attributed to the questionable physiological meaning of ARC, since the RAST is considered a valid test for anaerobic parameters assessment (Balciunas et al. 2006; Zacharogiannis et al. 2004; Zagatto et al. 2009).

In spite of the fact that the present investigation provides relevant information regarding RAST, $\mathrm{Lac}_{\mathrm{Min}}$ and CV application in shuttle futsal testing, it is impossible at this moment to discuss about the suitability and validity of these tests for this sport. Future investigations comparing gold standard protocols (i.e. maximal lactate steady state and maximal accumulated oxygen deficit) with RAST, Lac $_{\text {Min }}$ and CV results in shuttle exercise could validate these protocols for futsal.

\section{Conclusion}

The results of this study provide novel information for aerobic and anaerobic assessment of futsal players using laboratory tests applied in the field. Despite the scientific contribution about RAST, LaC $_{\text {Min }}$ and CV applications in shuttle futsal testing, the data from this study mainly contribute to approach science and practical application. Nowadays the futsal schedule is full of championships and tournaments, and many evaluation days for physical variables assessment are not welcome. Thus, in this study, we have showed relevant information to deal with this problem. We have demonstrated that futsal coaches may apply both Lac $_{\text {Min }}$ test (including RAST) and CV protocol in one or three evaluation days, respectively, and obtain relevant information of both aerobic and anaerobic 
metabolisms. Additionally, despite the CV protocol requires at least three evaluation days, it is possible to apply this test during the warm-up.

On the other hand, we also suggest that if one or another test was chosen, coaches must evaluate and reevaluate using the same test, since the RAST, $\mathrm{Lac}_{\text {Min }}$ test and CV protocol provide aerobic and anaerobic results with different physiological meanings. Therefore, the present study concludes that the RAST, LaC Min test and the CV may be successfully applied in shuttle futsal testing; however, coaches and researches should be aware that, depending on the test applied, different aerobic and anaerobic results can be obtained.

\section{References}

Araujo G.G., Papoti M., Manchado F.B., Mello M.A., Gobatto C.A. Protocols for hyperlactatemia induction in the lactate minimum test adapted to swimming rats. Comp Biochem Physiol A Mol Integr Physiol. 2007; 148 (4): 888-892.

Balciunas M., Stonkus S., Abrantes C., Sampaio J. Long term effects of different training modalities on power, speed, skill and anaerobic capacity in young male basketball players. J Sports Sci Med. 2006; 5 (1): 163-170.

Bar-Or O., Dotan R., Inbar O. A $30 \mathrm{sec}$. all-out ergometer test - its reliability and validity for anaerobic capacity. Isr J Med Sci. 1977; 13 (4): 126-130.

Barbero-Alvarez J.C., Soto V.M., Barbero-Alvarez V., Granda-Vera J. Match analysis and heart rate of futsal players during competition. J Sports Sci. 2008; 26 (1): 63-73.

Berthoin S., Baquet G., Dupont G., Van Praagh E. Critical velocity during continuous and intermittent exercises in children. Eur J Appl Physiol. 2006; 98 (2): 132-138.

Bull A.J., Housh T.J., Johnson G.O., Perry S.R. Effect of mathematical modeling on the estimation of critical power. Med Sci Sports Exerc. $2000 ; 32$ (2): 526-530.

Carter H., Jones A.M., Doust J.H. Effect of incremental test protocol on the lactate minimum speed. Med Sci Sports Exerc. 1999; 31 (6): 837-845.

Castagna C., Barbero-Alvarez J.C. Physiological demands of an intermittent futsal-oriented high-intensity test. J Strength Cond Res. 2010; 24 (9): 2322-2329.

Castagna C., D'Ottavio S., Granda Vera J., Barbero-Alvarez J.C. Match demands of professional Futsal: a case study. J Sci Med Sport. 2009; 12 (4): 490-494.

Copp S.W., Hirai D.M., Musch T.I., Poole D.C. Critical speed in the rat: implications for hindlimb muscle blood flow distribution and fibre recruitment. Journal of Physiology. 2010; 588 (10): 5077-5087.

Dekerle J., Brickley G., Hammond A.J., Pringle J.S., Carter H. Validity of the two-parameter model in estimating the anaerobic work capacity. Eur J Appl Physiol. 2006; 96 (3): 257-264.

Deminice R., Rosa F.T., Franco G.S., Jordao A.A., de Freitas E.C. Effects of creatine supplementation on oxidative stress and inflammatory markers after repeated-sprint exercise in humans. Nutrition. 2013; 29 (9): 1127-1132.

Dogramaci S.N., Watsford M.L., Murphy A.J. Time-motion analysis of international and national level futsal. J Strength Cond Res. 2011; 25 (3): 646-651.

Engel P.C., Jones J.B. Causes and elimination of erratic blanks in enzymatic metabolite assays involving the use of NAD+ in alkaline hydrazine buffers: improved conditions for the assay of L-glutamate, L-lactate, and other metabolites. Anal Biochem. 1978; 88 (2): 475-484.

Faude O., Kindermann W., Meyer T. Lactate threshold concepts: how valid are they? Sports Med. 2009; 39 (6): 469-490.

Fitzsimons M., Dawson B., Ware D., Wilkinson A. Cycling and running tests of repeated sprint ability. Aust J Sci Med Sport. 1993; 25 (5): 88-93.

Fukuda D.H., Smith A.E., Kendall K.L., Cramer J.T., Stout J.R. The determination of critical rest interval from the intermittent critical velocity test in club-level collegiate hockey and rugby players. J Strength Cond Res. 2011; 25 (4): 889-895.

Gobatto C.A., Scariot P.P.M., Ribeiro L.F.P., Manchado-Gobatto F.B. Critical load estimation in young swimming rats using hyperbolic and linear models. Comparative Exercise Physiology. 2013; 9 (6): 85-91.

Housh D.J., Housh T.J., Bauge S.M. A methodological consideration for the determination of critical power and anaerobic work capacity. Res Q Exerc Sport. 1990; 61 (4): 406-409. 
Housh T.J., Cramer J.T., Bull A.J., Johnson G.O., Housh D.J. The effect of mathematical modeling on critical velocity. Eur J Appl Physiol. 2001; 84 (5): 469-475.

Hughson R.L., Orok C.J., Staudt L.E. A high velocity treadmill running test to assess endurance running potential. Int J Sports Med. 1984; 5 (1): 23-25.

Jones A.M., Doust J.H. The validity of the lactate minimum test for determination of the maximal lactate steady state. Med Sci Sports Exerc. 1998; 30 (8): 1304-1313.

Jones A.M., Vanhatalo A., Burnley M., Morton R.H., Poole D.C. Critical power: implications for determination of $\mathrm{VO}_{2} \mathrm{max}$ and exercise tolerance. Med Sci Sports Exerc. 2010; 42 (10): 1876-1890.

Kindermann W., Simon G., Keul J. The significance of the aerobic-anaerobic transition for the determination of work load intensities during endurance training. European Journal of Applied Physiological Occupational Physiology. 1979; 42: 25-34.

Knoepfli-Lenzin C., Boutellier U. Lactate minimum is valid to estimate maximal lactate steady state in moderately and highly trained subjects. J Strength Cond Res. 2011; 25 (5): 1355-1359.

Lloyd B.B. The energetics of running: an analysis of world records. Adv Sci. 1966; 22 (15): 515-530.

MacIntosh B.R., Esau S., Svedahl K. The lactate minimum test for cycling: estimation of the maximal lactate steady state. Can J Appl Physiol. 2002; 27 (3): 232-249.

Monod H., Scherrer J. The work capacity of a synergic muscular group. Ergonomics. 1965; 8 (10): 328-338.

Rebelo A.N., Ascensao A.A., Magalhaes J.F., Bischoff R., Bendiksen M., Krustrup P. Elite futsal refereeing: activity profile and physiological demands. J Strength Cond Res. 2011; 25 (4): 980-987.

Ribeiro L., Balikian P., Malachias P., Baldissera V. Stage length, spline function and lactate minimum swimming speed. J Sports Med Phys Fitness. 2003; 43 (3): 312-318.

Rodrigues V.M., Ramos G.P., Mendes T.T., Cabido C.E., Melo E.S., Condessa L.A., Garcia E.S. Intensity of official Futsal matches. J Strength Cond Res. 2011; 25 (9): 2482-2487.

Roseguini A.Z., Silva A.S.R., Gobatto C.A. Determinations and relationships of the RAST anaerobic parameters, anaerobic threshold

and lactacidemia response obtained at the beginning, interval and the end of an official handball match. Revista Brasileira de Medicina do Esporte. 2008; 14 (1): 46-50.

Tegtbur U., Busse M.W., Braumann K.M. Estimation of an individual equilibrium between lactate production and catabolism during exercise. Med Sci Sports Exerc. 1993; 25 (5): 620-627.

Toubekis A.G., Vasilaki A., Douda H., Gourgoulis V., Tokmakidis S. Physiological responses during interval training at relative to critical velocity intensity in young swimmers. J Sci Med Sport. 2011; 14 (4): 363-368.

Wakayoshi K., Ikuta K., Yoshida T., Udo M., Moritani T., Mutoh Y., Miyashita M. Determination and validity of critical velocity as an index of swimming performance in the competitive swimmer. Eur J Appl Physiol Occup Physiol. 1992; 64 (2): 153-157.

Zacharogiannis E., Paradisis G., Tziortzis S. An evaluation of tests of anaerobic power and capacity. Medicine and Science Sports Exercise. 2004; 36.

Zagatto A.M., Beck W.R., Gobatto C.A. Validity of the running anaerobic sprint test for assessing anaerobic power and predicting shortdistance performances. J Strength Cond Res. 2009; 23 (6): 1820-1827.

Zagatto A.M., Gobatto C.A. Relationship between anaerobic parameters provided from MAOD and critical power model in specific table tennis test. Int J Sports Med. 2012; 33 (8): 613-620.

Zagatto A.M., Papoti M., Gobatto C.A. Anaerobic capacity may not be determined by critical power model in elite table tennis players. J Sports Sci Med. 2008; 7 (1): 54-59.

Cite this article as: Dalcheco Messias L.H., Carvalho de Andrade V., Rosante K.T., Buzatto de Lima T., Rodrigues Santa Cruz R.A., Martins de Oliveira R., de Barros Manchado-Gobatto F. Running Anaerobic Sprint Test, Lactate Minimum and Critical Velocity Protocol in Shuttle Futsal Testing. Central European Journal of Sport Sciences and Medicine. 2015; 12 (4): 5-15. 
